\title{
RESEARCHING THE RISKS OF RUSSIAN ENERGY COMPANIES IN THE CONTEXT OF RENEWABLE ENERGY SOURCES DEVELOPMENT
}

\author{
GALINA SERGEEVNA CHEBOTAREVA \\ Academic Department of Energy and Industrial Enterprises Management Systems, Ural Federal University, Russia
}

\begin{abstract}
As the global market for sustainable energy is growing, a trend towards the development of renewable energy sources (RES) is gaining prominence. Projects related to renewable energy are globally spread and find active government support in many countries. Despite similar trends in the Russian energy sector, its specific nature that is associated with the long-term development of traditional energy and large-scale power engineering projects creates many barriers to RES development. The article presents an interpretation of the competitiveness of Russian energy companies in terms of renewable energy development. The author presents a classification of risks based patterns that have been identified. Hypotheses about risk distribution along the stages of the life cycle of RES projects based on expert assessment are considered. The results of the study will be used for developing models and practical assessment of the competitiveness of Russian energy companies in terms of RES while taking into account the uneven distribution and varying quality characteristics of risks.

Key words: sustainable energy, energy company, renewable energy sources, distributed generation, competitiveness, risks, risk's distribution, investment project, project life cycle.
\end{abstract}

\section{INTRODUCTION}

Supported by the world community, the development of renewable energy contributes to the growing status of RES as the dominant source of energy and increases competition on national energy markets. The ability of embrace RES technologies is an important condition for improving the competitiveness of individual companies and the Russian economy in the long-term run.

However, RES development implies a long-term search for private and, as a rule, expensive capital to implement investment projects for RES. In addition, the rapid transition to renewable energy is accompanied by the appearance of specific risks.

Consequently, there is a difficult task of conducting not only theoretical but also applied research into the competitiveness of energy companies in terms of RES development and existing specific risks.

As of today, this issue has not been sufficiently studied in Russia. A lot of analysis in the field of RES that has been performed by the International Energy Agency (IEA), the International Renewable Energy Agency (IRENA), the Organization of the Petroleum Exporting Countries (OPEC) (IRENA Report [1]-[5], KPMG Report [6]) has practically no effect on the competitiveness of companies today.

As an outcome of the study being described, specific risks being carried by Russian energy companies in terms of renewable energy development have been identified and classified and hypotheses about the distribution of risks along project life cycles have been formulated and evaluated. In the future, it will make it possible to study how the level of an energy company's competitiveness changes throughout the progress of a project. It will also make it possible to develop highly effective programs for companies' competitiveness management. 


\section{COMPETITIVENESS AND RISKS OF ENERGY COMPANIES IN THE CONTEXT OF RES DEVELOPMENT}

There are a lot of approaches to defining the term "competitiveness" with regard to the energy sector in the modern literature. Within the framework of this study, competitiveness is defined with regard to the ultimate goal of giving its deterministic assessment for energy companies in terms of renewable energy. In a wider sense, an energy company's competitiveness describes its ability to economically cover the losses arising from internal and external risks and uncertainties stemming from the specific features of the energy market in terms of RES development. In a narrow sense, competitiveness is interpreted as a combination of these risks and the uncertainty.

The above definition requires the identification of the specific risks faced by the energy company characterizing its competitiveness in the context of renewable energy development.

\subsection{Specific risks of Russian energy companies in the context of RES development}

An examination of the global and Russian renewable energy markets (IRENA Report [5], Ermolenko et al. [7]) showed that the nature of these risks is influenced by specific support mechanisms. Initially, a relatively low investment attractiveness of RES required the government stimulus. The worldwide practice of awarding a premium to the price of electricity from RES (feed-in tariffs) was supplemented in 2011 with the idea of providing support based on the RES capacity charge. Since the middle of 2013, mechanisms have been introduced for selling the capacity of RES generators through annual competitive selection of investment projects; a range of target indicators for the period 2014-2020 years has been established (Resolution [8], ROSNANA Report [9]). Russia, like the majority of other countries, does not have a system of direct government subsidies for renewable energy.

Another peculiarity of identifying and assessing specific risks is the comparison of attained values of risk indicators for conventional energy and to those of RES technologies. First of all, it is essential to single out general financial risks that traditionally accompany the implementation of RES projects. These include (Domnikov et al. [10], [11], Munoz and Bunn [12]):

- credit risk,

- currency risk,

- inflation risk, etc.

These risks are due to the use of private capital in the implementation of RES projects, including resources of commercial banks and international financial institutions.

However, the most relevant risks to the study are the ones arising in the course of the implementation of RES projects and characterizing the features of the energy market with regard to renewable sources. Market analysis (IRENA Report [1], [2], Smil [13]), and expert assessments were used to identify such specific risks. Their brief description is presented below.

Incorrect localization of RES objects - inefficient regional distribution of renewable energy facilities. On the one hand, this risk is associated with the desire to achieve maximum performance of renewable electricity generation, and on the other hand, with the difficulty of forecasting the amount of electric power produced by some sources (e.g., solar, wind).

Instability of the mechanisms of government support of RES projects leads to the emergence of legislative risks. Frequent changes in support schemes for RES, a lack of financial protection scare investors away. Meanwhile, in the opinion of investors, the stability of support mechanisms, regardless of their type, is a guarantee of RES development (IFC Report [14]). 
Dependence of investors on government support at all stages of a project. Usually this is due to the volume and duration of the support being granted.

1. Frequent changes in support schemes contribute to the low efficiency of the mechanisms of government and regional stimulation of RES development in some areas (Daniilidis and Heber[15]).

2. The high cost of renewable energy: higher adjusted cost of renewable energy (LCOE) compared to traditionally generated energy(Ghoddusi [16], John [17]).

3. Low effectiveness of adoption of RES technologies: in comparison with the cost of replacement or repair of worn-out basic production assets of energy companies/adoption of new conventional energy technologies (John [17], Budischak et al. [18], Report [19]).

4. Environmental risks: change in energy companies' expenditures on environmental safety compared to conventional energy sources (Stanek et al. [20], Hdidouan and Staffell [21], Pryor et al. [22]).

5. Slow pace of RES market development: share of renewable energy in the energy balance, share of electricity generated by RES, "natural" demand on renewable energy.

6. High pace of conventional energy market development: the volume of current and prospective hydrocarbon reserves. It has a direct influence on demand, the cost of electricity and efficiency of RES projects.

7. Slow pace of distributed power generation development in the RES sphere.

8. Reduction in private investment in renewable energy projects due to lower investment attractiveness (Deloitte Report [23]).

\section{HYPOTHESIS ABOUT SPECIFIC RISKS DISTRIBUTION IN RES PROJECT LIFE CYCLE}

As part of this study four hypotheses were considered regarding risks distribution in the stages of the life cycle of a RES project.

\subsection{Characteristics of risks distribution hypotheses}

The hypotheses are based on assumptions about the changing quantity and quality (status) of risks. A brief description of these hypotheses is presented below.

- The first hypothesis assumes that the number of risks does not change over the main stages of the project life cycle. However, values of qualitative characteristics such as the probability of each risk and the total amount of the losses vary. This means that there is at least a minimal impact of each risk on the company's competitiveness at any stage of the project.

- The second hypothesis is based on the assumption that not only the quality but also the quantity of risks changes. Consequently, the combination of risks according to the stages of the life cycle is strictly individual. Consequently, the impact of some risks on competitiveness is observed only at certain stages, and at other stages the impact is null.

- The basis of the third hypothesis is the assumption that neither the status of the risks nor their quantity change. This distribution of the risks implies that the project is not influenced by market processes.

- The fourth hypothesis was introduced as mutually exclusive in relation to the first three: only the quantity of risks change in RES project stages. The risks quality remains unchanged.

Methodological characteristics of each hypotheses is presented in Table 1. 
Table 1: Differences of risk distribution hypotheses ${ }^{\mathrm{i}}$.

\begin{tabular}{|c|c|c|c|}
\hline \multirow{2}{*}{ Hypothesis } & \multirow{2}{*}{$\begin{array}{c}\text { Quantitative } \\
\text { changes to risks }\end{array}$} & \multicolumn{2}{|c|}{ Changes to risk status (quantity of risks) } \\
\cline { 3 - 4 } & - & Risks probability & Risk-induced losses \\
\hline 1 & + & + \\
\hline 2 & - & + \\
\hline 3 & + & - \\
\hline 4 & + & - \\
\hline
\end{tabular}

«+» means that indicator changed; «-» - did not change.

\subsection{Expert assessment of risks distribution hypotheses}

Expert assessment made it possible to rank the hypotheses. The main criterion for the ranking is the percentage of experts' votes about the plausibility of the hypotheses:

1. The second hypothesis $(45 \%)$;

2. The first hypothesis $(34 \%)$;

3. The third hypothesis $(20 \%)$;

4. The fourth hypothesis (less than $1 \%$ ).

The experts were heads of services and divisions of Russian energy company PJSC "T Plus Group".

According to the experts' opinion, the second hypothesis demonstrates the best response to market changes: the combination of risks and their status are flexible. This hypothesis requires the development of an integrated approach to identification and assessment of the risks taking into account the instability of the market environment. It is important to note that the first hypothesis, according to some experts, should be considered as a special case of the second one under certain economic conditions (only the quality indicators are flexible).

The third hypothesis is an example of full control by the government over the implementation of the project and elimination of the external effects of the market. Unplanned losses from the risk's impact must be refunded.

The preliminary assessment of the fourth hypothesis as mutually exclusive in relation to the other three was confirmed by expert analysis. The described situation was considered impossible.

As a result of the expert assessment, three hypotheses were selected (1-3) for the next stages of the study. Each of them requires general identification of risks. The second hypothesis also requires specific risk distribution along the stages of the project life cycle.

\section{RISKS DISTRIBUTION IN RES PROJECT LIFECYCLE}

In this study, risks distribution in three main phases of the project is considered: pre-investment (Pre-Inv), investment (Inv) and post-investment (Post-Inv) (Tappen et al. [24]).

4.1 Methodological approach to risks assessment in RES project life cycle

A complex approach (Domnikov and Chebotareva [25]) is proposed as a basic methodology for preliminary risks distribution in the RES project life cycle. It includes the following stages: 
1. Assessment of the current status of each risk;

2. Calculation of the maximum and minimum risk probability;

3. Ranking of the risks;

4. Graphical representation of risks;

5. Calculation of the risk level.

Assessment of the current status of each risk is performed by calculating the individual limits of the risk status with eqn (1) based on a Bayes method (Domnikov et al. [26]):

$$
\begin{gathered}
\ln \left(c_{i} q_{i}\right)-0.5 *\left(\left(X-M_{i}\right)^{T} * S_{i}^{-1} *\left(X-M_{i}\right)-\ln \left|S_{i}\right|\right)-\left(\ln \left(c_{i+1} q_{i+1}\right)-0.5 *\right. \\
\left.\left(\left(X-M_{i+1}\right)^{T} * S_{i+1}^{-1} *\left(X-M_{i+1}\right)-\ln \left|S_{i+1}\right|\right)\right),
\end{gathered}
$$

where $X$ is the variable vector in the space of risks under study; $M_{i}, M_{i+1}$ - expectations; $S_{i}$, Si+1-covariance matrices; qi, qi+1 - prior occurrence probability for objects of classes ${ }_{i}$ and $_{i+1}$; $c_{i}, c_{i+1}$-costs of error in the reference of objects to classes $i$ and $i+1$.

The obtained results make it possible to take the risk status to one of the groups: minimum (a) admissible (b) high (c) critical (d) risk effect level (REL).

Assessment of the status of risks and calculation of the maximum and minimum risk probability provide the basis for compiling a risk ranking and its graphical representation (Domnikov et al. [11]). At the final stage, the risk level is calculated with eqn (2) based on the aggregate risk theory (Domnikov et al. [27]):

$$
R=\frac{R^{\max }+R^{\min }}{2}
$$

where $\mathrm{R}$ is the risk level; $R^{\max }=\frac{1}{2} *\left(\sum_{j=1}^{n}\left(p_{j}^{\max } * p_{j+1}^{\max } * \sin \gamma_{j+1}\right)+p_{1}^{\max } * p_{n}^{\max } *\right.$ $\left.\sin \gamma_{n}\right)$ - maximum risk level; $R^{\text {min }}=\frac{1}{2} *\left(\sum_{j=1}^{n}\left(p_{j}^{\text {min }} * p_{j+1}^{\text {min }} * \sin \gamma_{j+1}\right)+p_{1}^{\text {min }} * p_{n}^{\text {min }} *\right.$ $\left.\sin \gamma_{n}\right)$ - minimum risk level; $p_{j}^{\max }$ - maximum $\mathrm{j}$-th risk probability; $\mathrm{p}_{\mathrm{j}+1}^{\max }$ - maximum $(\mathrm{j}+1)$ th risk probability; $\gamma_{j+1}-(j+1)$-th risk level of influence on competitiveness; $p_{j}^{\text {min }}$ - minimum $\mathrm{j}$-th risk probability; $\mathrm{p}_{\mathrm{j}+1}^{\min }$ - minimum $(\mathrm{j}+1)$-th risk probability.

The risk level is a dimensionless quantity and is used when assessing capital requirements for companies. This evaluation is conducted for each stage of the RES project. However, application of the presented approach is complicated by the fact that only some risks are of quantitative nature and are fit for assessment (by means of the identified indicators and relevant statistics); assessment of other risks is possible only with qualitative methods. Currently, this contradiction is solved by evaluating indicators of such risks based on expert judgment.

\subsection{Practical assessment of risks in RES project life cycle}

Using the methodology makes it possible to conduct preliminary risk assessment in the project life cycle in accordance with the three hypotheses. The results of the risk assessment are presented in Table 2. The set of risks in the project life cycle for the second hypothesis is identified by expert analysis. The third hypothesis is not included to Table 2 because the risk values throughout all phases coincide with the pre-investment phase of the first hypothesis.

The risk level is 1,11 .

Risk distributions in the RES project life cycle are shown in accordance with the volume of investments and cash flows in Figs 1-3. 
The study shows that in the case of the first and second hypothesis (Figs 1 and 2) the riskcurve starts to grow in the period of investment growth (investment period), as well as during the preparation of the RES facility for launch.

Refined risks distribution in the RES project lifecycle for the third hypothesis is shown in Fig. 3. This is a straight risk-line that does not change its values throughout all project stages.

The second hypothesis shows the adjusted risk level in the stages of the RES project in comparison with the first hypothesis. In the future, this will make it possible to calculate fewer requirements to the economic capital of the energy company (Domnikov et al. [28]) in case of a lower level of risk. On the other hand, if the initial risk in the third hypothesis was underestimated (in comparison with the second hypothesis), it would lead to the possibility of incomplete coverage of losses from risks due to incorrect calculation of the economic capital.

In the situation of a big number of hypotheses and specific interpretations of competitiveness the quantitative value of the competitiveness level of an energy company will significantly vary throughout the stages of the RES project life cycle. Therefore, research into the competitiveness of energy companies requires the development of a methodological approach that takes into account all the existing features of assessment.

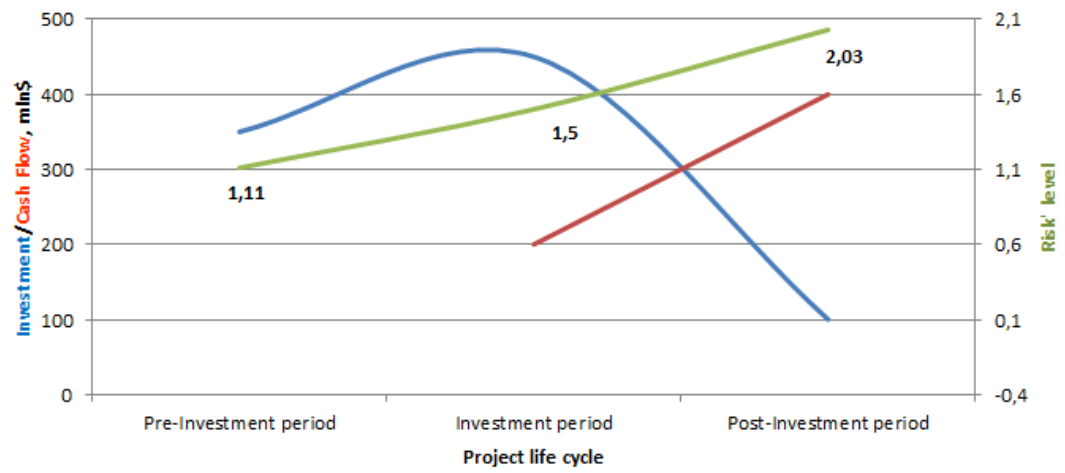

Figure 1: Risks distribution in RES project life cycle: first hypothesis.

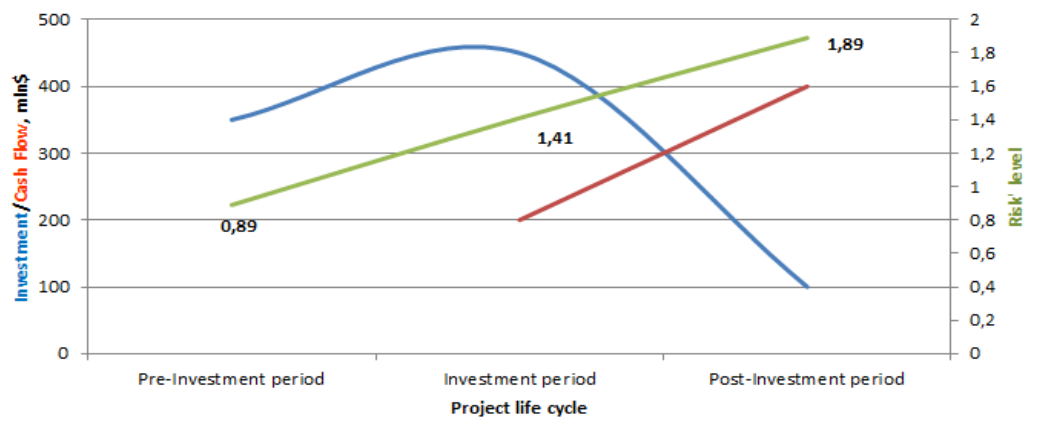

Figure 2: Risks distribution in RES project life cycle: second hypothesis. 


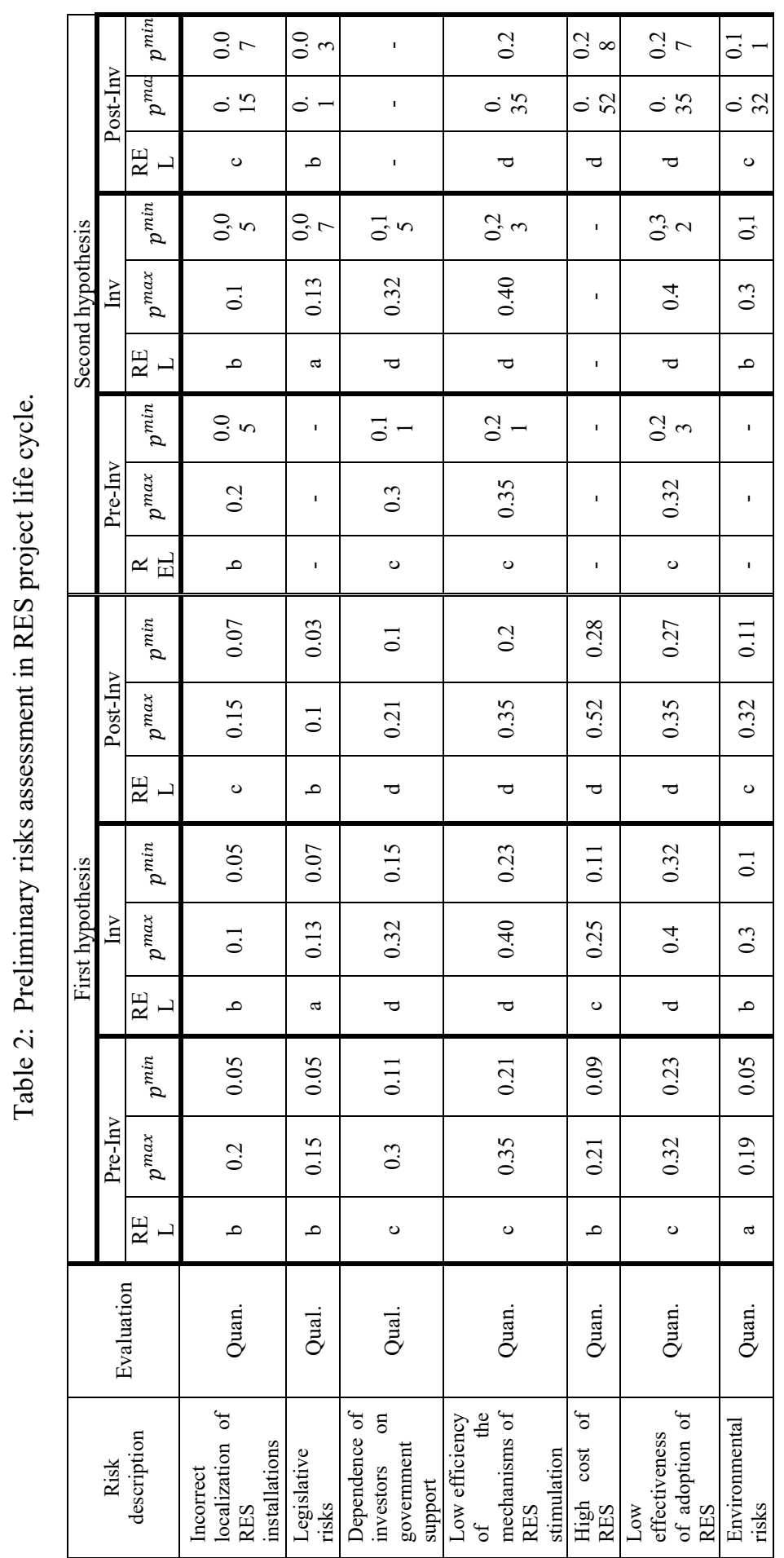




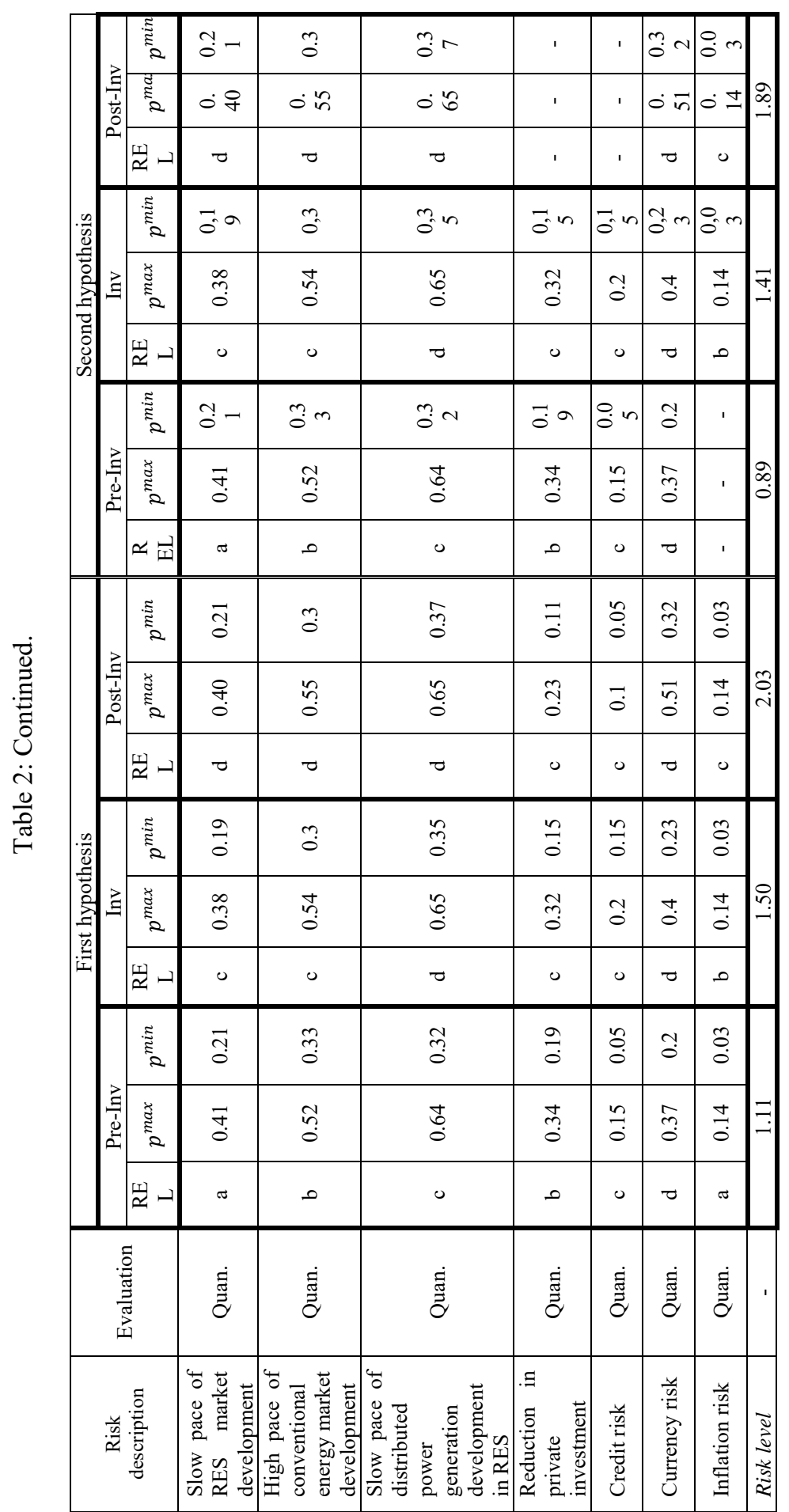




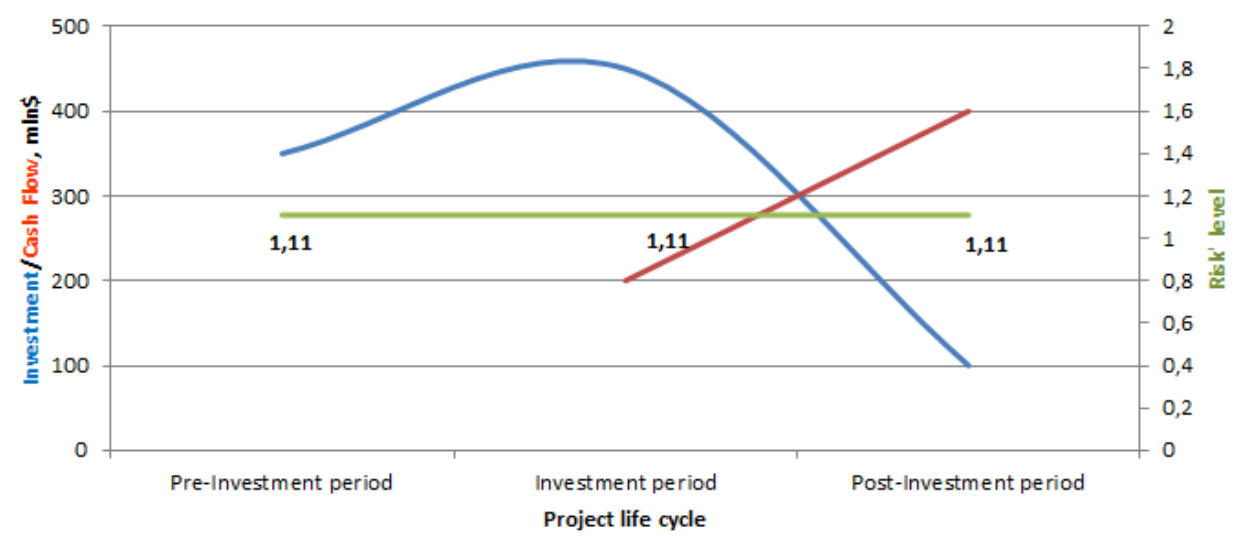

Figure 3: Risks distribution in RES project life cycle: third hypothesis.

\section{FEATURES OF THE ASSESSMENT OF ENERGY COMPANIES SPECIFIC RISK ASSOCIATED WITH RES}

Identification of the specific risks of the energy companies in the context of RES development and implementation of the hypotheses about risks distribution along project stages provide the basis for studying the features of risk assessment under specified conditions.

First, the specific nature of the RES market generates heterogeneous risks that cannot be assessed with standard methodological tools. Consequently, it will require the development of a special approach combining both quantitative and qualitative methods of risk assessment (Domnikov et al. [11], [28], Chebotareva and Domnikov [29]).

Second, the application of the theory of economic capital (Domnikov et al. [28], [30], Chebotareva and Domnikov [29]) becomes more complex due to changes in the indicator "exposure-at-default" (EAD), the maturity (M) of the project and the probability of default (PD) at each phase of the project.

Third, simultaneously changing characteristics of the quantity and quality of a risk (e.g. the second hypothesis) make it difficult to estimate the exact value of the risk. This requires an estimation of the "corridor" of risk fluctuations along the stages.

Fourth, the result of the assessment is a more accurate estimation of the economic capital of the energy company throughout the project stages. In case of a reduction in the economic capital the energy company can attract new investments; in the opposite situation - take action to reduce the risk.

\section{CONCLUSION}

The competitiveness of a company largely depends on its ability to quickly adapt to the challenges of sustainable energy (Mokhov and Stakhanov [31], Mokhov et al. [32]). One of these challenges - the development of RES technology - gives rise to many specific risks that threaten the stability of the company. Consequently, the task of effective risk management gains particular importance.

The conducted research made it possible to classify risks and develop hypotheses about their distribution in a RES project. Together with an expert assessment of the hypotheses, this provides the theoretical basis for the development of complex methodological tools for 
the study of the competitiveness of an energy company. The examination of different hypotheses allows one to develop a great number of scenarios. It will improve the efficiency of risk management programs of energy companies.

One of the complex methodological issues that calls for an immediate solution is the expediency of including the cost of parallel investment projects to the company's current economic capital value. Other promising areas of research are:

developing a mathematical apparatus enabling one to compare the results of the qualitative and quantitative risk assessment;

recalculation of the indicator of the level of loss given default (LGD), with regard to the phases of the project;

clarification of risks distribution hypotheses based on the study of special cases of changes in certain qualitative characteristics of risks.

\section{ACKNOWLEDGEMENT}

The work was supported with a grant of the Russian Science Foundation (project № 17-7810039).

\section{REFERENCES}

[1] International Renewable Energy Agency (IRENA). A Renewable Energy Roadmap. http://www.irena.org/DocumentDownloads/Publications/IRENA_REmap_2016_RU. pdf. Accessed on: 1 Jun. 2017.

[2] International Renewable Energy Agency (IRENA). Renewable Energy Prospects for the Russian Federation (REmap working paper). http://www.bigpowernews.ru/ photos/0/0_4fXu7sfSuLrr28VAQkCDTPQeLJHbumqP.pdf. Accessed on: 1 Jun. 2017.

[3] International Renewable Energy Agency (IRENA). Renewable energy highlights. http://www.irena.org/DocumentDownloads/Publications/IRENA_Renewable_energy highlights_July_2017.pdf. Accessed on: 10 Jul. 2017.

[4] International Renewable Energy Agency (IRENA). Off-grid renewable energy systems: status and methodological issues. http://www.irena.org/ DocumentDownloads/Publications/IRENA_Offgrid_Renewable_Systems_WP_2015.pdf. Accessed on: 15 Jun. 2017.

[5] International Renewable Energy Agency (IRENA). Renewable Energy Statistics 2017. http://www.irena.org/DocumentDownloads/Publications/IRENA_Renewable_Energy Statistics_2017.pdf. Accessed on: 20 Jun. 2017.

[6] KPMG. Green power 2011: The KPMG renewable energy M\&A report. https://assets.kpmg.com/content/dam/kpmg/pdf/2011/06/GreenPower2011.pdf.

Accessed on: 21 Jun. 2017.

[7] Ermolenko, G.V., Tolmacheva, I.S., Ryapin I.Y., Fetisova Y.A., Matshura A.A. \& Reutiva A.B., Handbook on renewable energy the European Union, Institute of Energy SRU GSE: Moscow, p. 96, 2016.

[8] Resolution of the Russian Government dated 28 May 2013 N 449 On the mechanism of stimulation of using renewables in the wholesale market of electric energy and power. http://base.garant.ru/70388616/. Accessed on: 15 Jun. 2017.

[9] RUSNANO. Russian renewable energy. http://www.rusnano.com/upload/ images/sitefiles/files/Presentation_Energy_Efficiency_ENES2013.pdf. Accessed on: 15 Jun. 2017.

[10] Domnikov, A., Chebotareva, G. \& Khodorovsky, M., Evaluation of investor attractiveness of power-generating companies: special reference to the development 
risks of the electric power industry. WIT Transactions on Ecology and the Environment, vol. 190, WIT Press: Southampton and Boston, pp. 199-210, 2014.

[11] Domnikov, A., Chebotareva, G. \& Khodorovsky, M., Unbiased investment risk assessment for energy generating companies: rating approach. International Journal of Sustainable Development and Planning, 12(7), pp. 1168-1177, 2017.

[12] Munoz, J.I. \& Bunn, D.W., Investment risk and return under renewable decarbonization of a power market. Policy, 1, pp. 87-105, 2013.

[13] Smil, V., Energy Myths and realities, AST-PRESS: Moscow, 272 p., 2012.

[14] International Finance Corporation (IFC). Russian politics in the sphere of renewable energy sources. http://www.ifc.org/wps/wcm/connect/ 6834db8040c81109b86ebd5d948a4a50/Green\%20Giant\%20RUS.pdf?MOD=AJPER ES. Accessed on: 20 Jun. 2017.

[15] Daniilidis, A. \& Herber, R., Impact of technical and economic uncertainties on the economic performance of a deep geothermal heat system. Renewable Energy, 114(B), pp. 805-816, 2017.

[16] Ghoddusi, H., Price risks for biofuel producers in a deregulated market. Renewable Energy, 114(B), pp. 394-407, 2017.

[17] John, S.G. \& Lakshmanan T., Cost optimization of dish solar concentrators for improved scalability decisions. Renewable Energy, 114(B), pp. 600-613, 2017.

[18] Budischak, C. et al., Cost-minimized combinations of wind power, solar power and electrochemical storage, powering the grid up to $99.9 \%$ of the time. J. Power Sources, 225, pp. 60-74, 2013.

[19] Windpower Cost Imperative Drives Monopiles to New Depths. http://www.windpoweroffshore.com/article/1210058/depth-cost-imperative-drivesmonopiles-new-depths. Accessed on: 1 Aug. 2017.

[20] Stanek, W., Czarnowska, L., Gazda, W. \& Simla, T., Thermo-ecological cost of electricity from renewable energy sources. Renewable Energy, Submitted for publication, 2017.

[21] Hdidouan, D. \& Staffell, I., The impact of climate change on the levelised cost of wind energy. Renewable Energy, 101, pp. 575-592, 2017.

[22] Pryor, S. et al., Analyses of possible changes in intense and extreme wind speeds over northern Europe under climate change scenarios, Dyn., pp. 189-208, 2012.

[23] Deloitte Establishing the Investment Case: Wind Power. http://tinyurl.com/deloittewind-investment-2014. Accessed on: 1 Aug. 2017.

[24] Tappen, S.J., Aschmann, V. \& Effenberger M., Lifetime development and load response of the electrical efficiency of biogas-driven cogeneration units. Renewable Energy, 114(B), pp. 857-865, 2017.

[25] Domnikov, A. \& Chebotareva, G., Development of risk management for power generating companies in developing countries. Audit and Financial Analysis, 3, pp. 305-310, 2015.

[26] Domnikov, A., Chebotareva, G. \& Khodorovsky, M., Diagnostics of energy companies investor attractive based on methods of quality risk status identification. Audit and Financial Analysis, 6, pp. 77-83, 2014.

[27] Domnikov, A., Chebotareva, G. \& Khodorovsky, M., Increase the objectivity of the investment risks assessment of power-generating companies: rating approach. Bulletin of UrFU. Series Economics and Management, 4, pp. 87-97, 2014.

[28] Domnikov, A., Chebotareva, G. Khomenko, P. \& Khodorovsky, M., Risk-oriented investment in management of oil and gas company value. WIT Press, International Journal of Sustainable Development and Planning. 12(5), pp. 946-955, 2017. 
[29] Chebotareva, G. \& Domnikov, A., Assessment of competitiveness of power generating companies through risk-based approach: a case study of developing economies. International Journal of Energy Production and Management. The Quest for Sustainable Energy. WIT Press, 1(4), pp. 322-331, 2016.

[30] Domnikov, A., G. Khomenko, P. \& Chebotareva, G., A risk-oriented approach to capital management at a power generation company in Russia. WIT Transactions on Ecology and the Environment, WIT Press: Southampton and Boston, 186 pp. 13-24, 2014.

[31] Mokhov, V. \& Stakhanov, K., Modelling the Innovation Activity of an Enterprise. Bulletin of the South Ural State University. Series Mathematical Modelling, Programming \& Computer Software, 9(2), pp.130-134, 2016.

[32] Mokhov, V.G., Chebotareva, G.S. \& Demyanenko. T.S., Complex approach to assessment of investment attractiveness of power generating company. Bulletin of the South Ural State University. Series Mathematical Modelling, Programming \& Computer Software, 10(2), pp. 150-154, 2017. 